International Journal of Medical Arts 2020; 2 [3]: 528-534.

Available online at Journal Website
https://ijma.journals.ekb.eg/
Main subject [Medicine [Obstetrics]]

Original article

\title{
Predictive Value of both Serum Placental Protein-13 Level and Uterine Artery Doppler for Prediction of Pre-Eclampsia
}

\author{
Marwa Samir El-Hassab[a]; Rashed Mohammed Rashed[b]; Magdy Zaky Elghannam[c]; Alaa Eldin \\ Mahmoud Megahed $[\mathrm{b}]$
}

Department of Obstetrics and Gynecology, Ministry of Health, Egypt $[\mathrm{a}]$

Department of Obstetrics and Gynecology, Damietta Faculty of Medicine, Al-Azhar University, Egypt ${ }^{[b]}$

Department of Clinical Pathology, Damietta Faculty of Medicine, Al-Azhar University, Egypt[c]

Corresponding author: Marwa Samir El-Hassab

Email: mzattia11@gmail.com

Received at: January 12, 2020; Revised at: June 02, 2020; Accepted at: June 02, 2020; Available online at: June 02, 2020

DOI: 10.21608/ijma.2020.22342.1081

\section{ABSTRACT}

Background: Preeclampsia [PE] is one of the commonest medical emergencies. It had high morbidity for the mother and her infant. Early diagnosis could reduce such morbidity.

Aim of the work: To evaluate the role of maternal serum placental protein [PP13] levels and uterine artery Doppler in early prediction and prognosis of preeclampsia.

Patients and Methods: The study included 60 pregnant women in their first and early second trimester with high risk for preeclampsia. Patients were divided into three groups: control, mild and sever preeclampsia. All were subjected to proper history taking, clinical and obstetrical examination, laboratory investigations and ultrasound examination.

Results: Cesarean delivery was significantly increased in preeclampsia compared to controls [ $55 \%$ of mild and $20 \%$ of severe disease compared to $15 \%$ of controls]. Both uterine artery resistance index [RI] and pulsatility index [PI] were significantly increased in PE when compared to control and in severe when compared to mild PE groups. Finally, PP13 was significantly decreased in patients with severe PE [171.7 \pm 35.9$]$ when compared to mild PE $[213.1 \pm 41.8]$ or control group [254.8 \pm 51.1$]$. In addition, there was significant decrease in cases with mild PE when compared to control group. Finally, there was inverse [negative], moderate and statistically significant correlation between PP13 from one side and each of systolic BP, diastolic BP, uterine artery RI and PI. In addition, both RI and PI were proportionally correlated with $\mathrm{PI}$ and $\mathrm{RI}$.

Conclusion: The present study showed that PP13 combined with PI or RI can predict PE with a good sensitivity and specificity.

Keywords: Preeclampsia; Placental Protein-13; Uterine Artery; Doppler; Prediction.

This is an open access article under the Creative Commons license [CC BY] [https://creativecommons.org/licenses/by/2.0/]

Please cite this article as: El-hassab MS, Rashed MR, Elghannam MZ, Megahed AM. Predictive Value of both Serum Placental Protein-13 Level and Uterine Artery Doppler for Prediction of Pre-Eclampsia. IJMA 2020; 2[3]: 528-534.

* Main subject and any subcategories have been classified according to research topic. 


\section{INTRODUCTION}

Preeclampsia [PE] is one of the leading etiologies of maternal morbidity and mortality all over the world complicating about $5 \%$ of pregnancies ${ }^{[1]}$.

The diagnosis is based mainly on elevated blood pressure [BP], especially new onset hypertension [systolic blood pressure $\geq 140 \mathrm{mmHg}$, or diastolic $\geq$ $90 \mathrm{mmHg}$ ], with proteinuria or other manifestations such as renal impairment, thrombocytopenia, hepatic dysfunction, pulmonary edema, or cerebral/ visual disturbances [2].

Abnormal remodeling of the maternal spiral arteries is the main pathoetiologic mechanism of PE. This remodeling creates an ischemic placenta with release of different factors responsible for pathophysiology of the disease [3]. However, the actual pathophysiological mechanisms of PE remain unclear and management options are relatively limited [4]. Thus, accurate prediction of PE is crucial to identify patients who require more intensive monitoring, with early intervention by potential preventive measures [5].

Prediction algorithms using maternal risk factors, doppler study of uterine arteries, mean arterial blood pressure and other maternal biochemical factors were developed with variable predictive value [6].

Placental protein 13 [PP13] is an exclusive protein expressed by the placenta. It plays a significant role in adhesion of the placenta to the uterus and expansion of maternal arteries by remodeling ${ }^{[7]}$.

It was studied as an early predictor of PE [8.9] and was recently incorporated in composite predictive models along with uterine artery Doppler findings and other biochemical markers [10]. However, no consensus about its predictive role is reached yet.

\section{AIM OF WORK}

The current work aims to evaluate the role of maternal serum PP13 levels and uterine artery Doppler in early prediction and prognosis of preeclampsia.

\section{PATIENTS AND METHOD}

The present study is a prospective longitudinal clinical study was conducted at Al-Azhar University Hospital, Damietta in the period from January, 2018 through December, 2018. The study protocol was approved by the local institutional review board (IRP) and all patients gave informed consent before participation in the study. The study includes 60 pregnant women (convenient sample) in their first trimester and early second trimester between $11^{+0}$ and $13^{+} 6$ weeks' gestation with high risk for developing PE. Risk factors included family history of preeclampsia, diabetes and hypertension, history of smoking and obesity. Patients were included in the study on the basis of the following criteria and were divided into three groups control [Group 1], mild preeclampsia [Group 2] and sever preeclampsia [Group 3].

Inclusion criteria were: 1] Singleton pregnancy with gestational age between $11^{+0}$ and $13^{+6}$ weeks, 2] Age 20-30 years old, and 3] Nullipara \& multipara

Exclusion criteria were: 1] Multiple pregnancy and any disease accompany with increased PP13 as [renal disease, chronic hepatitis, cardiovascular disease, and some hematological disease], 2] Diabetes, and 3] Essential hypertension.

All patients were subjected to the following: $A]$. Proper history taking, B]. Thorough clinical and obstetrical examination, measurement of systolic and diastolic blood pressure, urine check for proteinuria and check for edema, C]. Laboratory investigation included 1]- Routine investigation [Complete blood counting [CBC]: by automated blood counter [SysmexXs- 500I, Japan]. Serum creatinine, serum Albumin, serum total protein, ACR in urine, serum cholesterol: measured by fully automated chemistry analyzer [Bechman coulter AU 480, Irland], 2] Specific investigation [Assessment of serum PP13 levels in the first trimester by taking $5 \mathrm{ml}$ from blood to make ELISA technique using Techan Austria GmbH 5082 Grodig Austria Model: Sunrise Basic Tecan]. It was carried out as descried by El Sherbiny et al. [7], D. Doppler assessment of uterine artery done by Voluson 730 [USA] via a transabdominal 3.5-MHz. Using pulsed wave Doppler, flow velocity waveforms from the ascending branch of the uterine artery at the point closest to the internal os are obtained, with the Doppler sampling gate set at $2 \mathrm{~mm}$. Care is taken to use the smallest angle of insonation $[<30]$ in order to achieve the highest systolic and end-diastolic velocities. When three similar successive waveforms are obtained, the pulsatility index $[\mathrm{PI}]$ and resistivity index $[\mathrm{RI}]$ can be measured. The mean PI \& RI were calculated as the 
average reading.

Statistical analysis: Data were fed to statistical package for social science (SPSS) versions 17 under the platform of Microsoft Windows. Numerical data were presented in the form of mean $\pm S D$ while categorical variables were expressed in the form of count and percentage. Comparison of numerical data were performed by one-way analysis of variance (ANOVA), while categorical data were done using Chi-square test. ROC curve analysis was used to detect diagnostic test sensitivity, and correlation between variables was calculated by Spearman's correlation coefficient. $P$ value $<0.05$ was considered significant.

\section{RESULTS}

Results of the present study revealed that, there was no significant difference between control group, mild and severe preeclampsia, regarding patient demographics, gravidity parity, gestational age, or miscarriage. However, there was significant difference regarding mode of delivery, where cesarean delivery was significantly increase in patients with preeclampsia when compared to control group [ $55 \%$ of patients with mild disease and $20 \%$ of severe disease compared to $15 \%$ of controls delivered by cesarean delivery] [Table 1].

In the present study, blood pressure was significantly increased in patients with preeclampsia when compared to control group and in severe when compared to mild PE. In addition, both uterine artery $\mathrm{RI}$ and $\mathrm{PI}$ were significantly increase in PE when compared to control and in severe when compared to mild PE groups. Finally, PP13 was significantly decreased in patients with severe PE $[171.7 \pm 35.9]$ when compared to mild PE [213.1 \pm 41.8$]$ or control group [254.8 \pm 51.1$]$. In addition, there was significant decrease in cases with mild PE when compared to control group. Otherwise, no significant difference was reported between groups regarding other laboratory data, clinical data or fetal anthropometry [Table 2].

In addition, there was inverse [negative], moderate and statistically significant correlation between PP-13 from one side and each of systolic $\mathrm{BP}$, diastolic $\mathrm{BP}$, uterine artery $\mathrm{RI}$ and $\mathrm{PI}$. In addition, both RI and PI were proportionally correlated with PI and RI [Table 3].

Finally, PPI-13 had a sensitivity of $78.1 \% \mathrm{n}$ diagnosis of PE at a cutoff of 221.9 , and a sensitivity of $75.0 \%$ in diagnosis of severe $P E$ at a cutoff value of 179.9 . On the other side, PI had sensitivity of $81.3 \%$ and $75.0 \%$, while RI had sensitivity of $75.0 \%$ and $68.8 \%$, and both PP12 combined with PI had sensitivity of $90.6 \%$ and $75.0 \%$, while PP13 combined with RI had sensitivity of $84.4 \%$ and $75.0 \%$ for diagnosis of $P E$ and severe $P E$ respectively [Table 4].

Table [1]: Comparison between the studied groups regarding patient characteristics

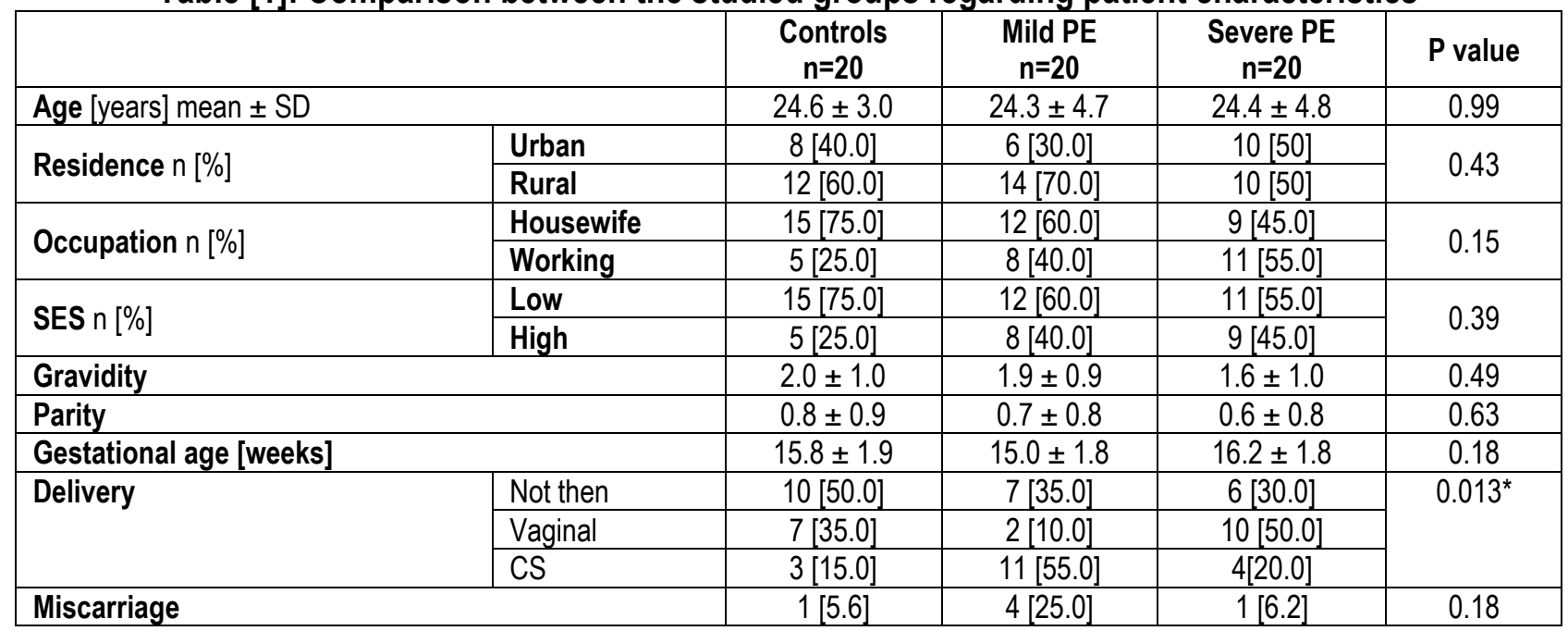

PE: Preeclampsia, SES: Socioeconomic status; APH: antepartum hemorrhage, IUGR: Intrauterine growth restriction 
Table [2]: Clinical, laboratory data, fetal anthropometry among studied groups

\begin{tabular}{|c|c|c|c|c|c|}
\hline & & $\begin{array}{c}\text { Controls } \\
n=20\end{array}$ & $\begin{array}{l}\text { Mild PE } \\
n=20\end{array}$ & $\begin{array}{c}\text { Severe PE } \\
n=20\end{array}$ & $P$ value \\
\hline \multirow{5}{*}{$\begin{array}{l}\text { Clinical } \\
\text { Data }\end{array}$} & $\mathrm{BMI}\left[\mathrm{Kg} / \mathrm{m}^{2}\right]$ mean $\pm \mathrm{SD}$ & $34.4 \pm 4.2$ & $34.2 \pm 3.2$ & $36.0 \pm 5.0$ & 0.45 \\
\hline & $\mathrm{SBP}[\mathrm{mmHg}]$ mean $\pm \mathrm{SD}$ & $113.6 \pm 3.3$ & $145.6 \pm 4.8^{*} \#$ & $179.4 \pm 13.9^{*}$ & 0.0001 \\
\hline & $\mathrm{DBP}[\mathrm{mmHg}]$ mean \pm SD & $75.0 \pm 4.2$ & $96.6 \pm 4.7$ & $113.1 \pm 13.8$ & 0.0001 \\
\hline & Pulse $[\mathrm{mmHg}]$ mean $\pm \mathrm{SD}$ & $88.1 \pm 6.9$ & $83.8 \pm 7.0$ & $89.1 \pm 8.0$ & 0.1 \\
\hline & Temperature [mmHg] mean $\pm \mathrm{SD}$ & $37.0 \pm 0.2$ & $37.0 \pm 0.2$ & $36.9 \pm 0.3$ & 0.51 \\
\hline \multirow{9}{*}{$\begin{array}{l}\text { Laboratory } \\
\text { Data }\end{array}$} & $\mathrm{Hb}[\mathrm{gm} / \mathrm{dll}]$ & $11.4 \pm 1.3$ & $11.7 \pm 1.0$ & $10.7 \pm 1.2$ & 0.057 \\
\hline & Platelets $\left[\times 10^{\wedge} 3 / \mathrm{ml}\right]$ & $266.8 \pm 51.7$ & $270.1 \pm 64.2$ & $234.8 \pm 60.4$ & 0.17 \\
\hline & WBCs $\left[\times 10^{\wedge} 3 / \mathrm{ml}\right]$ & $7.2 \pm 1.5$ & $6.6 \pm 1.7$ & $7.6 \pm 1.7$ & 0.20 \\
\hline & AST [IU/ml] & $32.6 \pm 11.5$ & $27.7 \pm 7.9$ & $34.8 \pm 9.3$ & 0.11 \\
\hline & ALT [IU/ml] & $38.3 \pm 18.2$ & $29.3 \pm 7.5$ & $35.8 \pm 10.2$ & 0.12 \\
\hline & Serum Albumin [mg/dl] & $3.8 \pm 0.3$ & $3.7 \pm 0.2$ & $3 \pm 0.3$ & 0.44 \\
\hline & Serum Creatinine [mg/dl] & $0.8 \pm 0.2$ & $0.8 \pm 0.1$ & $1.3 \pm 0.1$ & 0.34 \\
\hline & Serum Urea [mg/dl] & $31.9 \pm 15.8$ & $27.3 \pm 3.8$ & $24.9 \pm 15.8$ & 0.08 \\
\hline & PP13 [pg/ml] & $254.8 \pm 51.1$ & $213.1 \pm 41.8^{\star} \#$ & $171.7 \pm 35.9^{*}$ & $<0.001$ \\
\hline \multirow{3}{*}{$\begin{array}{l}\text { Fetal } \\
\text { Anthropometry }\end{array}$} & $\mathrm{BPD}[\mathrm{mm}]$ & $36.3 \pm 5.2$ & $34.5 \pm 4.8$ & $33.3 \pm 5.4$ & 0.29 \\
\hline & $\mathrm{FL}[\mathrm{mm}]$ & $21.7 \pm 4.7$ & $19.8 \pm 4.6$ & $18.3 \pm 4.6$ & 0.3 \\
\hline & $\mathrm{AC}[\mathrm{mm}]$ & $107.8 \pm 15.3$ & $101.6 \pm 12.7$ & $100.9 \pm 16.9$ & 0.21 \\
\hline \multirow{2}{*}{$\begin{array}{l}\text { Uterine artery } \\
\text { Doppler }\end{array}$} & $\mathrm{RI}$ & $0.73 \pm 0.07$ & $0.76 \pm 0.08^{*} \#$ & $0.81 \pm 0.05^{*}$ & 0.008 \\
\hline & $\mathrm{PI}$ & $1.67 \pm 0.26$ & $1.85 \pm 0.25^{\star} \#$ & $2.0 \pm 0.12^{\star}$ & $<0.001$ \\
\hline
\end{tabular}

SBP: systolic blood pressure, DBP: diastolic blood pressure. PE: preeclampsia, Hb: hemoglobin, WBCs: White blood cells, AST: Aspartate transferase, ALT: Alanine transferase, PP13: Placental protein-13, BPD: Biparietal diameter, FL: femur length, AC: abdominal circumference, RI: resistive index, PI: pulsatility index. * Significant versus controls; \# significant results versus severe PE

Table [3]: Correlation between PP13 and ultrasound with various clinical and laboratory data

\begin{tabular}{|c|c|c|c|c|c|c|}
\hline & \multicolumn{2}{|c|}{ PP13 } & \multicolumn{2}{|c|}{$\mathbf{R I}$} & \multicolumn{2}{|c|}{ PI } \\
\hline & $r$ & $p$ & $r$ & $p$ & $r$ & $p$ \\
\hline Age & 0.12 & 0.38 & 0.07 & 0.62 & 0.035 & 0.8 \\
\hline Gravidity & -0.017 & 0.90 & -0.04 & 0.76 & -0.046 & 0.74 \\
\hline Parity & -0.007 & 0.96 & 0.025 & 0.85 & 0.01 & 0.94 \\
\hline Gestational age & -0.15 & 0.28 & 0.08 & 0.56 & 0.09 & 0.49 \\
\hline BMI & 0.067 & 0.64 & 0.11 & 0.42 & 0.03 & 0.79 \\
\hline SBP & -0.57 & $<0.001$ & 0.38 & 0.005 & 0.51 & $<0.001$ \\
\hline DBP & -0.58 & $<0.001$ & 0.32 & 0.019 & 0.47 & $<0.001$ \\
\hline Pulse & 0.009 & 0.94 & -0.01 & 0.93 & -0.07 & 0.58 \\
\hline Temperature & -0.017 & 0.91 & -0.25 & 0.07 & -0.22 & 0.11 \\
\hline $\mathrm{Hb}$ & 0.12 & 0.38 & -0.049 & 0.73 & -0.06 & 0.56 \\
\hline Platelets & 0.14 & 0.31 & -0.19 & 0.17 & -0.28 & 0.14 \\
\hline WBCs & -0.11 & 0.42 & 0.01 & 0.94 & 0.12 & 0.38 \\
\hline AST & -0.03 & 0.78 & -0.06 & 0.67 & -0.04 & 0.74 \\
\hline ALT & 0.06 & 0.66 & -0.08 & 0.54 & -0.04 & 0.75 \\
\hline Serum Albumin & 0.056 & 0.7 & 0.2 & 0.16 & 0.09 & 0.5 \\
\hline Serum Creatinine & 0.08 & 0.58 & -0.14 & 0.3 & -0.07 & 0.59 \\
\hline Serum Urea & -0.097 & 0.5 & -0.04 & 0.75 & 0.028 & 0.84 \\
\hline PP13 & & & -0.42 & 0.002 & -0.46 & 0.001 \\
\hline BPD & -0.15 & 0.26 & 0.086 & 0.54 & 0.1 & 0.46 \\
\hline FL & -0.13 & 0.36 & 0.04 & 0.75 & 0.07 & 0.62 \\
\hline$A C$ & -0.15 & 0.27 & 0.046 & 0.74 & 0.08 & 0.57 \\
\hline RI & -0.42 & 0.002 & & & 0.88 & $<0.001$ \\
\hline $\mathrm{PI}$ & -0.46 & 0.001 & 0.88 & $<0.001$ & & \\
\hline
\end{tabular}

PE: preeclampsia, BMl: body mass index, SBP: systolic blood pressure, DBP: diastolic blood pressure, Hb: hemoglobin, WBCs: White blood cells, AST: Aspartate transferase, ALT: Alanine transferase, PP13: Placental protein-13, BPD: Biparietal diameter, FL: femur length, $\mathrm{AC}$ : abdominal circumference, $\mathrm{RI}$ : resistive index, $\mathrm{PI}$ : pulsatility index. 
Table [4]: Value of PP13 in prediction of PE and PE severity

\begin{tabular}{|l|c|c|c|c|c|c|c|c|c|c|}
\hline & \multicolumn{2}{|c|}{ PPI-13 } & \multicolumn{2}{c|}{ PI } & \multicolumn{2}{c|}{ RI } & \multicolumn{2}{c|}{ PP13 combined with PI } & \multicolumn{2}{c|}{ PP13 combined with RI } \\
\cline { 2 - 11 } & PE & Severity & PE & Severity & PE & Severity & PE & Severity & PE & Severity \\
\hline Cut-off & 221.9 & 179.9 & 1.99 & 2.0 & 0.8 & 0.81 & & & & \\
\hline AUC & 0.81 & 0.81 & 0.76 & 0.77 & 0.73 & 0.67 & 0.86 & 0.83 & 0.83 & 0.82 \\
\hline P value & 0.0001 & 0.003 & 0.002 & 0.009 & 0.007 & 0.11 & 0.0001 & 0.001 & 0.0001 & 0.002 \\
\hline Sensitivity & 78.1 & 75.0 & 81.3 & 75.0 & 75.0 & 68.8 & 90.6 & 75.0 & 84.4 & 75.0 \\
\hline Specificity & 88.9 & 87.5 & 72.2 & 68.7 & 66.7 & 50.0 & 77.8 & 75.0 & 66.7 & 75.0 \\
\hline
\end{tabular}

\section{DISUCSSION}

The present study aims to evaluate the role of maternal serum PP13 levels in combination with uterine artery Doppler in early prediction and prognosis of preeclampsia. Comparison between the studied groups regarding the reported investigations showed that PE patients had significantly lower PP13 when compared with controls. Also, patients with mild PE had significantly higher PP13 when compared with those with severe PE. These findings are in agreement with the study of Odibo et al. [11]. In their prospective study on 40 PE women and 410 controls, PE women had significantly lower levels of PP13. Also, our findings are in accordance with the Egyptian study of El Sherbiny et al. [7], who compared serum levels of PP13 between 50 PE women and 50 healthy controls. The maternal serum values of PP13 in the preeclamptic group were [157.9 $\pm 45.5 \mathrm{pg} / \mathrm{mL}$ ], which is markedly reduced than control group [225.3 $\pm 67.3 \mathrm{pg} / \mathrm{mL}]$. Likewise, in the study of Meiri et al.[8], PP13 values were significantly reduced in PE when compared with pregnant healthy controls. The association between PP13 and PE severity was recognized in the study of Moslemi Zadeh et al. [12]. In their case-control study on 1500 women, patients with severe PE had significantly lower PP13 levels when compared with patients with mild PE and controls as measures in the first or second trimesters. Moreover, in the study of De Villiers et al. [13], the authors reported that in severe PE, the median PP13 value was 35.8 $\mathrm{pg} / \mathrm{mL}$ and in PE pregnancies delivered before the week 34 , the median concentration was was 30.6 $\mathrm{pg} / \mathrm{mL}$, while in controls, it was $54.8 \mathrm{pg} / \mathrm{mL}$.

In contradiction to these results, Seravalli et al. [14], found that in low risk 668 patients who did not obtain aspirin, PP-13 values were not associated with pre-eclampsia, small for gestational age (SGA) or the both of them. Also, in the study of Chalova et al. [5], there were no significant differences in the mean values of PP13 between 11-13 weeks of pregnancy and 20 weeks of gestation in the control and PE groups. The current work found that PP13 is a good predictor of PE development. These results agree with Romero et al. ${ }^{[16]}$ who found that serum PP13 values in the first trimester was significantly reduced in patients who had preterm and earlyonset $P E$ than in those with normal pregnancies. Also, in the study of Luo and Han [9] on 33 preeclamptic and 71 healthy pregnancies, the authors found that maternal serum levels of PP13, sFlt-1 and FSLT3 play an important role in predicting late-onset preeclampsia. In addition, the former study of De Villiers et al. [13], found that first trimester serum PP13 can predict the development of severe preeclampsia at the third trimester.

In contrast, a subsequent meta-analysis found that PP13 of the first trimester, combined with other maternal characteristics and other serum biomarkers was insufficient for screening and prediction of females at risk[17]. Also, in the study of Ceylan et al. [18], on 30 pre-eclampsia patients and 90 control pregnant women, there was no significant relationship between PP-13 and early preeclampsia, nor with late pre-eclampsia. In addition, the present study found that uterine artery RI in prediction of PE had a sensitivity and specificity of $75.0 \%$ and $66.7 \%$ respectively. This agrees with Bhattacharyya et al. [19] study, who studied the role of uterine artery $\mathrm{RI}$ at mid-trimester in prediction of preeclampsia. They found that sensitivity and specificity were 73.33 and $86.48 \%$ in high-risk and 57.14 and $95.83 \%$ in low-risk group, successively.

Also, our study found that uterine artery PI could predict PE at a sensitivity and specificity of $81.3 \%$ and $72.2 \%$. However, in the study of Demers et al. [20], first-trimester uterine artery [UtA] pulsatility index [PI] was associated with preterm but not with term PE. However, in the study of Myatt et al. [21], uterine artery Doppler measurements prior to 21 weeks of gestation [median 16.6 weeks] showed low (poor) sensitivity for prediction of preeclampsia overall in a well-characterized, low-risk, nulliparous females.

Importantly, the present study showed that PP13 
combined with $\mathrm{PI}$ or RI can predict PE with a good sensitivity and specificity. These results are supported by the conclusions of Giguère et al. [22].

In their systematic review, they found that in highrisk females, the combination of PP13 and pulsatility index in first trimester yielded a $90 \%$ and $90 \%$ for sensitivity and specificity respectively. Moreover, in the study of Khalil et al. [23], the authors examine the predictive value of the combination of first-trimester serum PP13, uterine artery Doppler PI and pulse wave analysis and to assess concurrent and contingent strategies using this combination for assessing the risk of pre-eclampsia in females at high-risk. They found that combination of PP13, uterine artery $\mathrm{PI}$ and pulse-wave analysis is promising for the prediction of PE in females at higher risk and may be of value in the clinical practice.

In comparison, the study of Spencer et al.[24], found that late second-trimester PP13 alone is unlikely to be of value in prediction of PE and early $\mathrm{PE}$, and its predictability does not augmented when coupled with second-trimester Doppler PI or other potential biochemical indicators.

Also, in the study of Akolekar et al. [25], the authors concluded that while PP13 is implicated in the pathogenesis of impaired placentation and subsequent occurrence of early-PE, estimation of this placental product is unlikely to be useful in screening for the disease at 11-13 weeks.

In conclusion, the present study showed that PP13 combined with PI or RI can predict PE with a good sensitivity and specificity. However, these data must be used in caution due to small sample size included in each group. Future, large scale studies are recommended before globalization of these results.

\section{Financial and Non-Financial Relationships and Activities of Interest}

None

\section{REFERENCES}

1. Perucci LO, Corrêa MD, Dusse LM, Gomes KB, Sousa LP. Resolution of inflammation pathways in preeclampsiaa narrative review. Immunol Res. 2017 Aug; 65[4]:774-789. [DOI: 10.1007/s12026-017-8921-3].

2. Sones JL, Davisson RL. Preeclampsia, of mice and women. Physiol Genomics. 2016 Aug 1; 48 [8]: 565-72. [DOI:10.1152/physiolgenomics.00125.2015].
3. Logue OC, George EM, Bidwell GL. Preeclampsia and the brain: neuralcontrol of cardiovascular changes during pregnancy and neurological outcomes of preeclampsia. Clin Sci [Lond]. 2016 Aug 1; 130 [16]: 1417-34. [DOI: 10.1042/CS20160108].

4. Bakrania B, Duncan J, Warrington JP. The Endothelin Type AReceptor as a Potential Therapeutic Target in Preeclampsia. Int J Mol Sci. 2017 Feb 28;18[3]. pii: E522. [DOI:10.3390/ijms18030522].

5. Rodriguez A, Tuuli MG, Odibo AO. First-, Second-, and Third-Trimester Screening for Preeclampsia and Intrauterine Growth Restriction. Clin Lab Med. 2016 Jun; 36[2]:331-51. [DOI: 10.1016/j.cll.2016.01.007].

6. Poon LC, Nicolaides KH. Early prediction of preeclampsia. Obstet Gynecol Int.; 2014:297397. [DOI:10.1155/ 2014/ 297397].

7. EI Sherbiny WS, Soliman A, Nasr AS. Placental protein 13 as an early predictor in Egyptian patients with preeclampsia, correlation to risk, and association with outcome. J Investig Med. 2012 Jun;60[5]:818-22. [DOI:10.2310/JIM.0b013e31824e9a68].

8. Meiri H, Sammar M, Herzog A, Grimpel YI, Fihaman G, Cohen A, et al. Prediction of preeclampsia by placental protein 13 and background risk factors and its prevention by aspirin. J Perinat Med. 2014 Sep; 42[5]:591-601. [DOI: 10.1515/jpm-2013-0298].

9. Luo Q, Han X. Second-trimester maternal serum markers in the prediction of preeclampsia. J Perinat Med. 2017 Oct 26; 45[7]:809-816. [DOI: 10.1515/jpm-2016-0249].

10. Chang Y, Chen X, Cui HY. New Predictive Model at 11[+0] to 13[+6] Gestational Weeks for Early-Onset Preeclampsia with Fetal Growth Restriction. Reprod Sci. 2017 May; 24[5]:783-789. [DOI: 10.1177/ 1933719116669053].

11. Odibo AO, Zhong Y, Goetzinger KR, Odibo L, Bick JL, Bower CR, et al. First-trimester placental protein 13, PAPP-A, uterine artery Doppler and maternal characteristics in the prediction of pre-eclampsia. Placenta. 2011; 32[8]:598-602. [DOI: 10.1016/j.placenta. 2011. 05. 006].

12. Moslemi Zadeh N, Naghshvar F, Peyvandi S, Gheshlaghi P, and Ehetshami S. PP13 and PAPP-A in the First and Second Trimesters: Predictive Factors for Preeclampsia? ISRN Obstet Gynecol. 2012; 2012:263871. [DOI:10.5402/2012/263871].

13. De Villiers CP, Hedley PL, Placing S, Wøjdemann KR, Shalmi AC, Carlsen AL, et al. Placental protein-13 [PP13] in combination with PAPP-A and free leptin index [fLI] in first trimester maternal serum screening for severe and early preeclampsia. Clin Chem Lab Med. 2017;56[1]:65-74. [DOI:10.1515/cclm-2017-0356].

14. Seravalli V, Grimpel YI, Meiri H, Blitzer M, Baschat AA. Relationship between first-trimester serum placental protein-13 and maternal characteristics, placental Doppler studies and pregnancy outcome. J Perinat Med. $2016 \mathrm{Jul}$ 1; 44[5]:543-9. [DOI: 10.1515/.jpm-2015-0324]. 
15. Chalova KI, Pehlivanov BK, Amaliev IG, Amaliev GI, Raycheva RD, Ivanovska MV. Maternal Serum Concentrations of Corin, Endoglin, PP13, and sFIt-1 and their Changes with Advancement of Pregnancy and Correlation with Doppler of Uterine Arteries. Folia Med [Plovdiv]. 2018 Dec 1; 60[4]:558-564. [DOI: 10.2478/ folmed-2018-0025].

16. Romero R, Kusanovic JP, Than NG, Erez O, Gotsch F, Espinoza J, et al. First-trimester maternal serum PP13 in the risk assessment for preeclampsia. Am J Obstet Gynecol. 2008; 199[2]: 122.e1-122.e11. [DOI: 10.1016/ j.ajog.2008.01.013].

18. Ceylan N, Ozaksit G, Unlu BS, Yildiz Y, Yilmaz S, Agaca F. Can first trimester placental protein-13 and pregnancyassociated plasma protein-A predict pre-eclampsia in Turkish women? J Obstet Gynaecol. 2014 Aug; 34[6]:4825. [DOI:10.3109/01443615.2014.911832].

19. Bhattacharyya SK, Kundu S, Kabiraj SP. Prediction of preeclampsia by midtrimester uterine artery Doppler velocimetry in high-risk and low-risk women. J Obstet Gynaecol India. 2012 Jun;62[3]:297-300. [DOI: 10.1007/ s13224-012-0219-8].

20. Demers S, Boutin A, Gasse C, Drouin O, Girard M, Bujold E. First-Trimester Uterine Artery Doppler for the Prediction of Preeclampsia in Nulliparous Women: The Great Obstetrical Syndrome Study. Am J Perinatol. 2019 Jul; 36[9]:930-935. [DOI: 10.1055/s-0038-1675209].
21. Myatt L, Clifton RG, Roberts JM, Spong CY, Hauth JC, Varner MW, et al. Eunice Kennedy Shriver National Institute of Child Health and Human Development [NICHD] Maternal-Fetal Medicine Units Network [MFMU]. The utility of uterine artery Doppler velocimetry in prediction of preeclampsia in a low-risk population. Obstet Gynecol. 2012 Oct; 120[4]:815-22. [DOI:10.1097/AOG.0b013e $31826 \mathrm{af7fb}$.

22. Giguère $Y$, Charland $M$, Bujold $E$, Bernard $N$, Grenier $S$, Rousseau $F$, et al. Combining biochemical and ultrasonographic markers in predicting preeclampsia: a systematic review. Clin Chem. 2010 Mar; 56 [3]: 361-75. [DOI:10.1373/clinchem.2009.134080].

23. Khalil A, Cowans NJ, Spencer K, Goichman S, Meiri H, Harrington K. First-trimester markers for the prediction of pre-eclampsia in women with a-priori high risk. Ultrasound Obstet Gynecol. 2010 Jun; 35[6]:671-9. [DOI:10.1002/ uog.7559].

24. Spencer K, Cowans NJ, Chefetz I, Tal J, Kuhnreich I, Meiri H. Second-trimester uterine artery Doppler pulsatility index and maternal serum PP13 as markers of preeclampsia. Prenat Diagn. 2007 Mar;27[3]:258-63. [DOI:10.1002/pd.1664].

25. Akolekar R, Syngelaki A, Beta J, Kocylowski R, Nicolaides KH. Maternal serum placental protein 13 at 11 13 weeks of gestation in preeclampsia. Prenat Diagn 2009; 29[12]:1103-1108. [DOI: 10.1002/pd.2375]. 